\title{
Design and Evaluation of Novel Scalability Techniques for Adaptation over Heterogeneous Networks
}

\author{
Sanusi Muhammad (Dr.) ${ }^{1}$, Abdul Hamid Sadka (Prof.) ${ }^{2}$ \\ ${ }^{I}$ Student Member, IEEE, ${ }^{2}$ Senior Member, IEEE \\ Department of Computer \& Electronic. Engineering. Brunel University Uxbridge, UK.
}

\begin{abstract}
This paper addresses the issues concerned with the provision of scalable video services over heterogeneous networks particularly with regards to dynamic adaptation and user's acceptable quality of service. In order to provide and sustain an adaptive and network friendly multimedia communication service, a suite of techniques that achieved automatic scalability and adaptation are developed using H.264/AVC Extension codec platform. The objective, subjective and real time performances of the techniques are evaluated to assess the Quality of Service $(Q o S)$ provided to diverse users with variable constraints and dynamic resources. The techniques are further evaluated with view to establish their performance against state of the art scalable and none-scalable techniques. Several experiments and simulations revealed that the proposed techniques outperformed state-of-the-art and none-scalable(SL) techniques. The designed techniques provide an automated scalability adaptation on the video stream and showed up to 50\% gain in scalability adaptation against single layer $(S L)$ and none-combined scalability techniques.
\end{abstract}

Keywords: Adaptation, Dynamic-Scalability, H.264/AVC, Heterogeneous-Networks, Scalability.

\section{Introduction}

The current and future anticipation in the increase of multimedia applications and devices has motivated the need for improved scalability adaptation for the wide range of applications and heterogeneous channels resources requirements. The dynamic structure of internet and it's best effort service cannot guarantee picture quality for videoconferencing, video-telephony, surveillance, telemedicine (medical consultation at a distance), computer based online training and teaching applications. The dynamic and unpredicted changing characteristic of network channels induces delays and hence bit-errors and deteriorated picture quality.

The designed and evaluated techniques support an automatic and adaptive scalability to diverse networks time changing conditions. To implement this, the design provides a multiple layer combined scalability among temporal, quality and spatial scalabilities. Each of temporal, quality and spatial scalability is particularly proficient to specific applications and conditions. Hence the combination enhances its performance and benefits. Temporal refer to the smoothness of picture, Spatial is the size or detail on the picture and Quality is the fidelity of the video signal [1]. H.264/AVC was originally designed to be a codec with long term objectives (H.26L) as its tools are everyday experimented and redesigned for improved efficiency [2]. Hence there is a large room for further research and improvement since in most cases the gap in rate-distortionoptimisation performance to single layer is still significant [3].

\section{Methodology And Approach}

This research is aimed to achieve a dynamic scalability system within multi-channel environment. To achieve this, a preventive control method which control network based on its predicted conditions is considered. In reactive control, decisions are only made when problems occurred and thereby allowing possible congestion. Other approaches employed include developed and evaluated scalability techniques and heterogeneous network simulator. A purposely built heterogeneous networks simulator is built to simulate the techniques and algorithms for real-time performance evaluation. In this case, an adaptation technique is employed into the network based on its predicted conditions. Other standard tools employed are H.264/AVC codec and YUV viewer. Several experiments are conducted with the codec with a number of standard ITU sequences to assess the performance of the techniques from variety of video sources. A generalized adaptation frame work is obeyed. The frame work structured that any scalability or adaptation solution shall certify minimum constrains for intended environment preferences [4].

Apart from section 1 and 2 which are introduction and methodology respectively. The remaining parts are organized as follows: section 3 to section 6 covered the developed techniques with their evaluations and section 7 discussed their comparison. Section 8 and 9 presented the authors acknowledgement and conclusion respectively.. 


\section{Temporal And Quality Technique (T+Q)}

In this technique, a temporal multiplexer partition the original video sequence into two sets of video sequences. The sets of video sequences can be more than two producing more enhancement layers with variable bit-rates for a robust bug free bit-stream. Each of the video sequence is fed to individual encoder. Each of the encoder is designed to generate a QoS level unlike the others. As shown in Fig. 1, $\mathrm{t}+\mathrm{q}$ scalability is achieved between the base(BL) and enhancement layers(ELs). The BL which is the reference layer generates a minimum quality picture with quantisation parameter value $\left(\mathrm{Q}_{\mathrm{p}}\right)$ less than that of EL $\mathrm{Q}_{\mathrm{P}}$ and a bit-rate less than that of EL bit-rate. The implanted temporal scalability allows generation of temporal scalable layers which are of distinct quality levels and priorities. The hierarchical temporal prediction of the video frames produces the temporal layers at dissimilar frame rates. The number of temporal layers depends on the number of pictures that are designed as a Group of Picture (GOP) in the bit-stream. A smaller number of the GOP size, will produce less scalable layers and coding efficiency. This is because every GOP is assigned an initial intra frame which usually results in undesirable number of bits escalating the transmission bit-rates and the frame rates. Fig. 1 shows the architecture and operational design of combined temporal and quality scalability technique. SADMA stands for Scalability Decision Making Algorithm in [5]. The algorithm select the suitable technique based on network reported status. An experiment is conducted with harbour video sequence, one of the ITU standard sequences. A QCIF resolution format is used with a maximum of 300 frames. $2 \times$ QCIF video original sequences are used and a number of twelve scalable layers are generated. Each of the layers takes a distinctive frame and bit-rates. This characteristic allows production of multiple quality layers embedded in the video stream. Also different quantisation levels are associated with the quality levels of the layers. For instance, L0 and L1 are encoded with $\mathrm{Q}_{\mathrm{p}}$ values 38.57 and 39.10 respectively. The video stream embeds a minimum and maximum frame rate of $0.4688 \mathrm{~Hz}$ and $15 \mathrm{~Hz}$ respectively. The variable frame rates were encoded with variable bit-rates of minimum and maximum of $38.40 \mathrm{~Kb} / \mathrm{s}$ and $235.10 \mathrm{~Kb} / \mathrm{s}$ discrete levels for each of the produced scalability layers. For a similar experiment with high resolution CIF format, fourteen scalability layers are produced with minimum and maximum encoded bit-rate/frame-rate of $91.10 \mathrm{~Kb} / \mathrm{s} / 0.4688 \mathrm{~Hz}$ and $588.60 \mathrm{~Kb} / \mathrm{s} / 30 \mathrm{~Hz}$ respectively.

\subsection{Objective Evaluation of $t+q$ Technique}

In order to objectively evaluate the performance of $\mathrm{t}+\mathrm{q}$ technique against $\mathrm{q}, \mathrm{SL}$ and state-of-the-art-techniques,

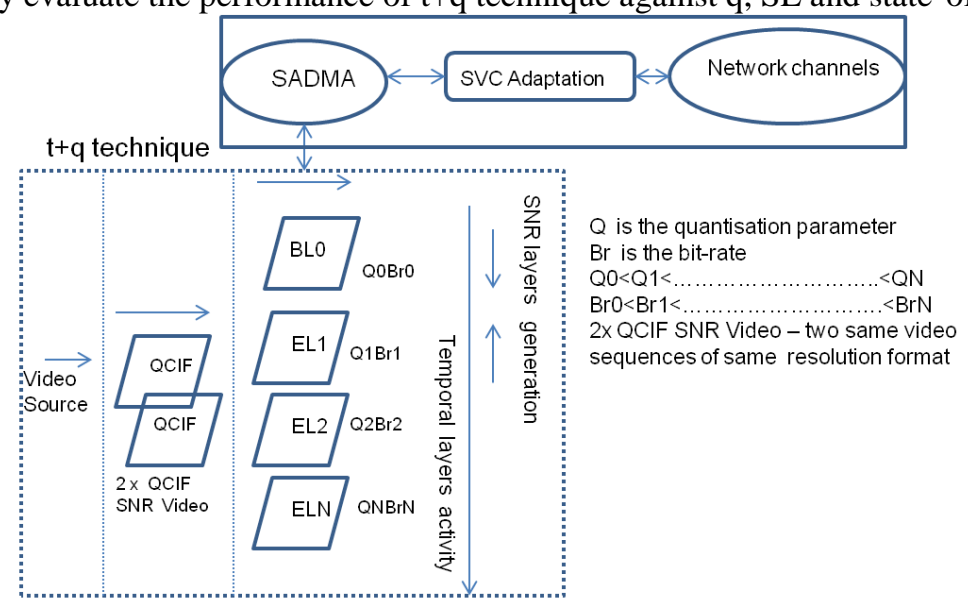

Fig. $1: \mathrm{t}+\mathrm{q}$ technique functional components with SADMA

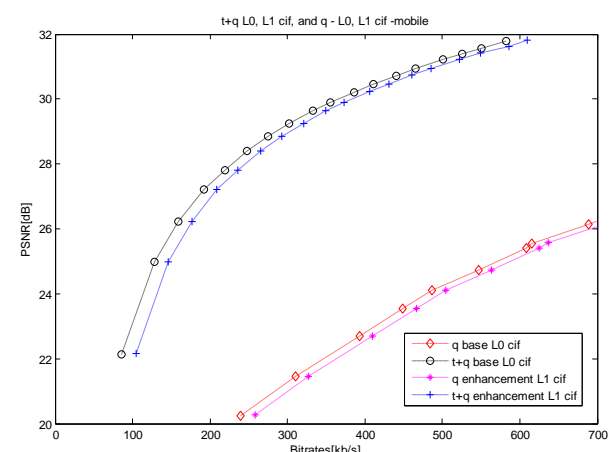

a. Mobile

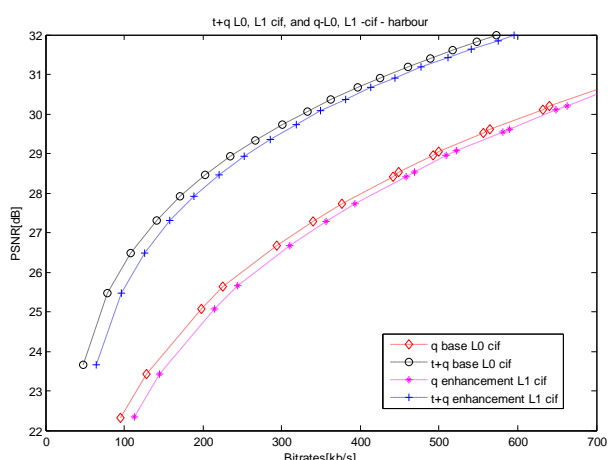

b. Harbour

Fig. $2: t+q$ technique evaluation with quality (q) technique $q$ and SL. 
Several experiments are conducted with foreman, city and harbour sequences. A number of videos with dissimilar motions and texture are used to assess the quality performance. The same methodology and coding tools are used for all the sequences. The experiment is set up as illustrated in Fig. 1 and the results are presented in Fig. 2(a, b).

Fig. 2 (a, b) shows that $t+q \mathrm{~L} 0$ has a better r.d.o. performance over $\mathrm{q}-\mathrm{L} 0$ technique. $\mathrm{q}-\mathrm{L} 0$ technique does not employ temporal scalability and hence is coded with less efficient predictions. To obtain a $\gamma$-luminance value of $22.1 \mathrm{~dB}, 25 \mathrm{~dB}$ and $28 \mathrm{~dB}$, a bit-rate of $99.8 \mathrm{~Kb} / \mathrm{s}, 140 \mathrm{~Kb} / \mathrm{s}$ and $210 \mathrm{~Kb} / \mathrm{s}$ is respectively required for $\mathrm{t}+\mathrm{q}-$ L0. On q-L0 technique, $89 \mathrm{~Kb} / \mathrm{s}, 130 \mathrm{~Kb} / \mathrm{s}$ and $200 \mathrm{~Kb} / \mathrm{s}$ bit-rates are correspondingly required. This gives a reduction of $10 \mathrm{~Kb} / \mathrm{s}$ for $\mathrm{t}+\mathrm{q}-\mathrm{L} 0$ over $\mathrm{q}-\mathrm{L} 0$ technique. $\mathrm{q}$ and $\mathrm{t}+\mathrm{q}$ techniques generate eight and twenty six scalable and adaptation layers respectively. Every one layer is designed to include variable bit-rates, frame-rates and a hierarchy of QoS levels. This supposed that $\mathrm{t}+\mathrm{q}-\mathrm{L} 0$ is less expensive than $\mathrm{SL}$ and is preferred for adaptation.

From Table I coding MPEG-4 and $\mathrm{t}+\mathrm{q}$ techniques at $3 / 6 \mathrm{f} / \mathrm{s}, \mathrm{t}+\mathrm{q}$ technique gained a reduction of 300bits, $189000 \mathrm{bits}$ and 21000bits per second over SL, BL and EL respectively. Similarly, with the $\mathrm{t}+\mathrm{q}$ technique profits gain of $14 \mathrm{~dB}, 5 \mathrm{~dB}$ and $9 \mathrm{~dB}$ for SL, BL and EL correspondingly are realised. These achieved gains are possible due to adaptive and variable $\mathrm{Qp}$ used for $\mathrm{t}+\mathrm{q}$ technique while MPEG-4 used a constant $\mathrm{Qp}$ at all coding bits and frame rates. At 7/10f/s coding frame rate, 12000bits, -3700bits and 19800bits per second reductions are achieved with $\mathrm{t}+\mathrm{q}$ technique against MPEG-4 scalability for SL, BL and EL respectively. Also 5dB, 5.12dB and $4.76 \mathrm{~dB}$ gains are realised with $\mathrm{t}+\mathrm{q}$ technique. Bits reduction of 27300bits, 19070bits and 38000bits is achieved for SL, BL and EL. when coding with 5/10f/s rates. Similarly at this frame rate $19.41 \mathrm{~dB}, 9.2 \mathrm{~dB}$ and $8.29 \mathrm{~dB}$ gain is achieved for SL, BL and EL respectively.

\subsection{Subjective Evaluation of $t+q$ Technique}

Double Stimulus Continuous Quality Scale (DSCQS) is employed as recommended by ITU-R BT.500 [6]. The DSCQS subjective assessment method is widely used to standardize the objective quality assessment method. A total number of fourteen participants were involved including experts and non-experts in the field. A 42 inch

Table I- $\mathrm{t}+\mathrm{q}$ technique and MPEG-4 quality and adaptation performance

\begin{tabular}{|c|c|c|c|c|c|c|c|c|}
\hline \multirow[t]{3}{*}{$(\mathrm{f} / \mathrm{s})$} & rate & $\underline{\mathrm{MP}}$ & & \multicolumn{5}{|c|}{$\underline{\text { H.264/t }+q \text { technique }}$} \\
\hline & \multicolumn{4}{|c|}{ Bitrates $(\mathbf{K b} / \mathbf{s}) /$ Luminance $(\gamma) \mathrm{dB}$} & \multicolumn{3}{|c|}{$\underline{\text { Bitrates }(\mathbf{K b} / \mathbf{s}) / \text { Luminance }(\gamma) \mathbf{d B}}$} & $\underline{Q p}$ \\
\hline & SL & $\mathrm{BL}$ & EL & Qp & SL & $\mathrm{BL}$ & EL & $\mathrm{SL} / \mathrm{BL} / \mathrm{EL}$ \\
\hline $3 / 6$ & $18 / 30.96$ & $28 / 30.89$ & $33 / 30.92$ & 13 & $15.05 / 44.93$ & $10.9 / 35.38$ & $11.78 / 40.01$ & $16.61 / 16.05 / 23.84$ \\
\hline 7.5 & $47 / 31.01$ & $32 / 30.97$ & $57 / 31.04$ & 13 & $35.39 / 35.92$ & $35.71 / 35.78$ & $38.76 / 35.80$ & $31.51 / 31.08 / 31.73$ \\
\hline $5 / 10$ & $37.5 / 31.0$ & $25 / 30.94$ & $44 / 31.00$ & 13 & $10.8 / 49.41$ & $6.07 / 39.29$ & $6.77 / 39.29$ & $11.11 / 10.55 / 20.30$ \\
\hline
\end{tabular}

monitor type (INTEL® Q45/Q43) was used for viewing. The viewing distance between the participants and the monitor was set to six times the height of the video as recommended by ITU $[6,7]$. Video sequences are run for at least two times and as requested. In each of the technique a left and right view video is displayed and run. One of the video is the reference video in spatial domain and the other is the technique output. The exact reference and the impaired sequences are hidden to the participants. A participant scores each sequence between ranges of bad to excellent score. The difference between the technique output score and the reference video score evaluates the quality of the technique picture output. The less the difference, the better the similarity between the two pictures. Fig. 5 presents the evaluation results. Fig. 3 and Fig. 4 present subjective quality videos for QCIF and CIF formats respectively.

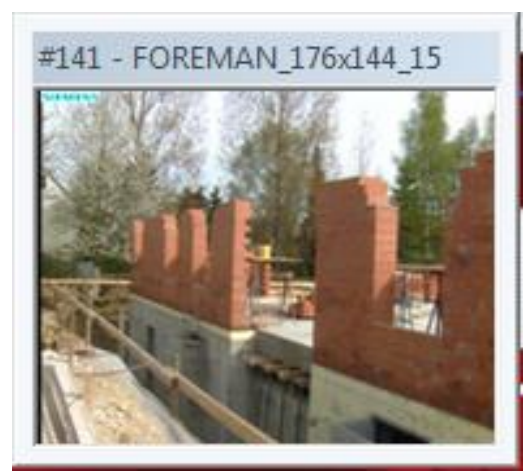

a. Pixel domain, frame 141

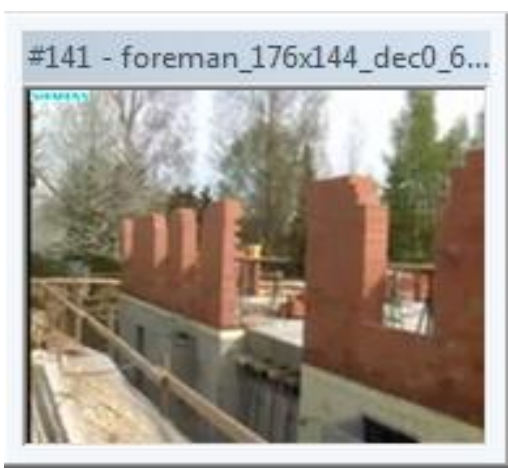

b. SL, $64 \mathrm{~Kb} / \mathrm{s}$, Frame 141

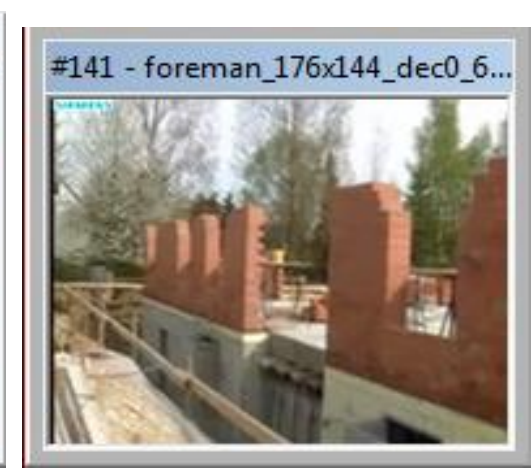

c. $\mathrm{t}+\mathrm{q}, 64 \mathrm{~Kb} / \mathrm{s}$, Frame 141 


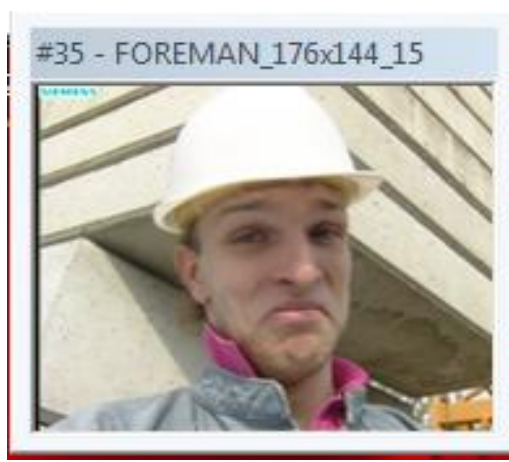

d. Pixel domain, Frame 35

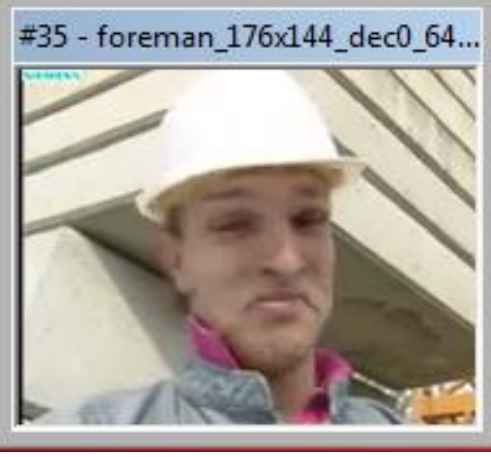

e. SL, $64 \mathrm{~Kb} / \mathrm{s}$, Frame 35

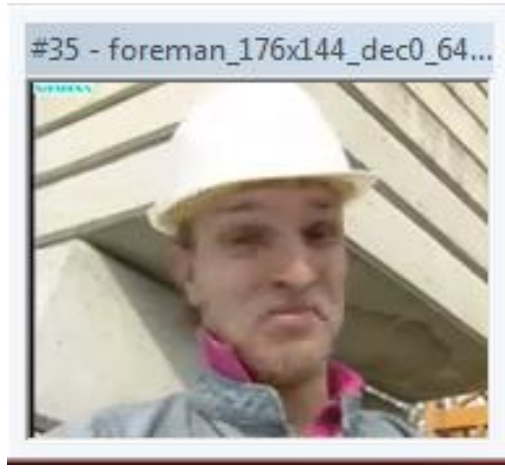

f. $\mathrm{t}+\mathrm{q}, 64 \mathrm{~Kb} / \mathrm{s}$, Frame 35

Fig. 3 : t+q- subjective quality evaluation (QCIF)

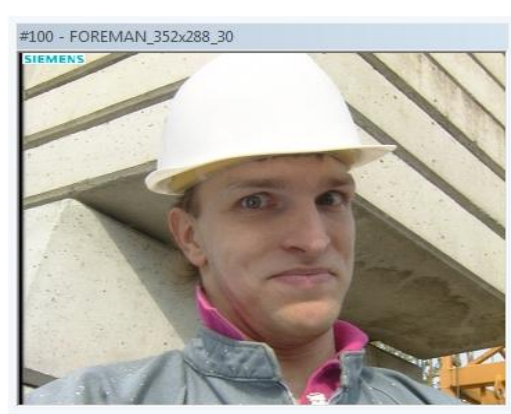

a. Pixel domain, frame 100

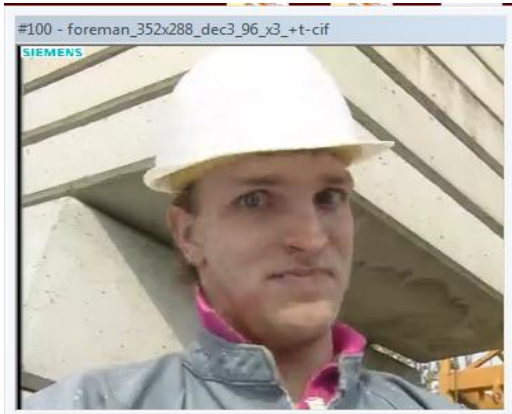

b.SL, $96 \mathrm{~Kb} / \mathrm{s}$, Frame 100, CIF

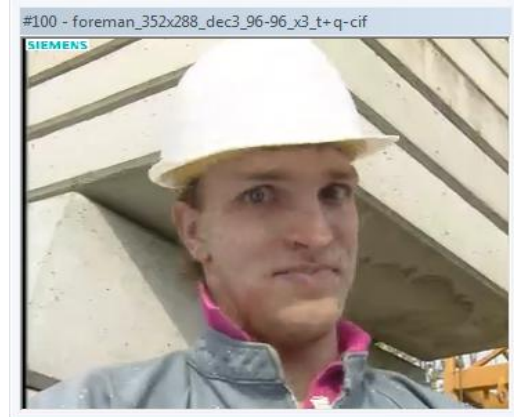

c. $t+q, 96 \mathrm{~Kb} / \mathrm{s}$, Frame 100, CIF

Fig. $4: \mathrm{t}+\mathrm{q}$ - subjective quality evaluation (CIF)

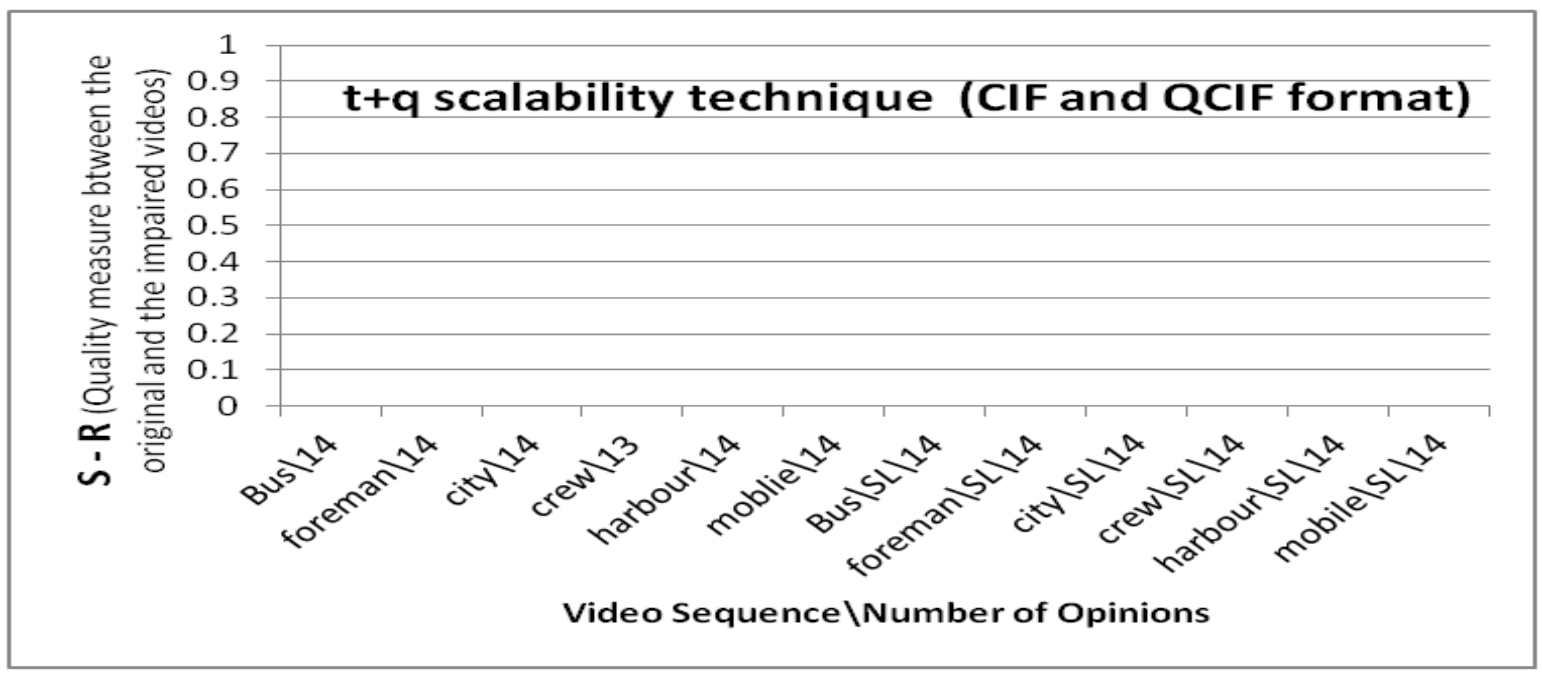

Fig. $5: \mathrm{t}+\mathrm{q}$ pair opinion score for original, $\mathrm{t}+\mathrm{q}$ and $\mathrm{SL}$ videos

\section{Temporal, Spatial And Quality Scalability Technique (T+S+Q)}

The combination of temporal, quality and spatial scalabilities may effect in better adaptation and scalability. This method therefore supports wider flexibility to multi-channel and clients. A minimum of three original layers will be required to enable this technique i.e. a minimum of two similar layers which enable quality scalability and one dissimilar spatial format layer to provide spatial picture scalability. With the additional number of layers, the inter-layer dependency is increased to produce lesser number of coding bits. From experimental result in Fig. 8, it is shown that at bit-stream size of $100 \mathrm{~KB}$, single layer (SL), $\mathrm{t}+\mathrm{q}, \mathrm{t}+\mathrm{s}$ and $\mathrm{t}+\mathrm{s}+\mathrm{q}$ techniques will be spending 170000bits, 169000bits, 169000bits and 135000bits per second respectively. $\mathrm{t}+\mathrm{s}+\mathrm{q}$ spent fewer bits due to high number of inter-layer dependency and better prediction within the layers and their frames. Fig. 6 illustrate $\mathrm{t}+\mathrm{s}+\mathrm{q}$ components and its link with SADMA algorithm. 


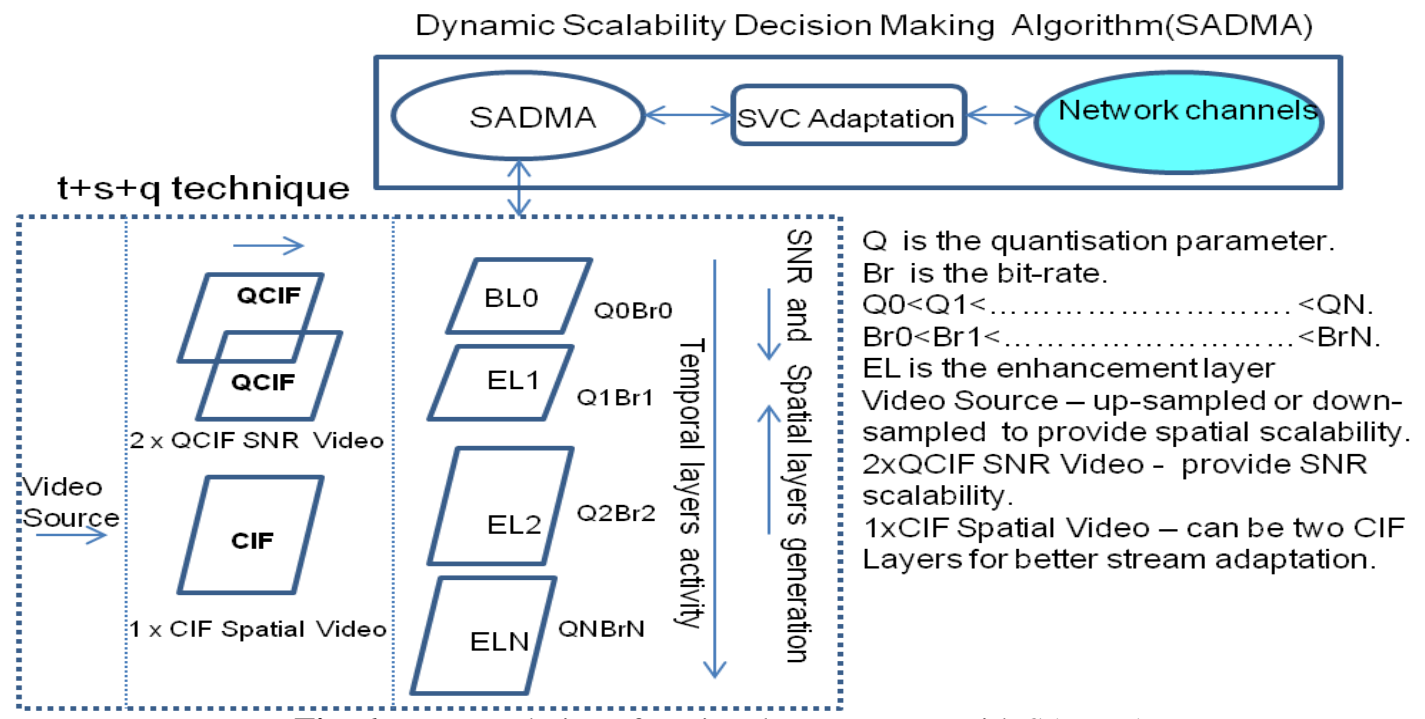

Fig. 6: $t+s+q$ technique functional components with SADMA

An experiment is conducted with harbour sequence. $2 \mathrm{xCIF}$ and $2 \mathrm{xQCIF}$ video sequences are used to enable a full scalability. A number of twenty-six scalable layers are produced (12xQCIF and 14xCIF). Each of the layers takes a unique frame and bit-rate and quantisation parameter values. This feature allows generation of multiple quality layers embedded in the video stream. A minimum of $0.4688 \mathrm{~Hz}$ and a maximum of $30.00 \mathrm{~Hz}$ frame rates were used. The variable frame rates were encoded with variable bit-rates having a minimum of $51.50 \mathrm{~Kb} / \mathrm{s}$ and a maximum of $739.10 \mathrm{~Kb} / \mathrm{s}$ discrete levels.

In a similar experiment with mobile sequence of 300 maximum frames, 12xQCIF layers and $14 x C I F$ layers are generated, a total of twenty-six scalable layers. The minimum bit-rate for this sequence is $33.70 \mathrm{~Kb} / \mathrm{s}$ and maximum of $864.20 \mathrm{~Kb} / \mathrm{s}$.

\subsection{Objective Evaluation of $t+s+q$ Technique}

Several experiments are conducted with a number of sequences namely foreman, harbour, city and bus images. The purpose is to objectively evaluate quality and adaptation performance of $\mathrm{t}+\mathrm{s}+\mathrm{q}$. The experimental results are presented on Fig. 7. From Fig. 7 (a), $150 \mathrm{~Kb} / \mathrm{s}, 200 \mathrm{~Kb} / \mathrm{s}$ and $250 \mathrm{~Kb} / \mathrm{s}$ are required to generate $27 \mathrm{~dB}$ quality value for $\mathrm{t}+\mathrm{q}, \mathrm{t}+\mathrm{s}$ and $\mathrm{t}+\mathrm{s}+\mathrm{q}$ techniques respectively. The spent bits are higher with the $\mathrm{t}+\mathrm{s}+\mathrm{q}$ in this layer production. Since $t+s+q$ technique generates more layers than $t+s$, other layers might be formed with enhanced adaptation characteristics. A better adaptation and r.d.o. for $\mathrm{t}+\mathrm{s}+\mathrm{q}$ (L1) technique is shown in bus sequence in Fig. 7 (b).

Table II shows that coding the stream at 75/10f/s, a bit reduction of $11100 \mathrm{bits},-4280 \mathrm{bits}$ and $-8840 \mathrm{bits}$ is achieved for SL, BL and EL for $\mathrm{t}+\mathrm{s}+\mathrm{q}$ scalability against MPEG-4 scalability. Correspondingly, a delta gain of $4.91 \mathrm{~dB}, 4.51 \mathrm{~dB}$ and $0.61 \mathrm{~dB}$ is obtained for SL, BL and EL respectively for $\mathrm{t}+\mathrm{s}+\mathrm{q}$ method against that of MPEG-4. It is observed that, $\mathrm{t}+\mathrm{s}+\mathrm{q}$ technique has gained an increased bit-rate while maintaining a higher quality than MPEG-4 at these rates, although a better quality is achieved from $\mathrm{t}+\mathrm{s}+\mathrm{q}$ technique. Another distinctive characteristic of $\mathrm{t}+\mathrm{s}+\mathrm{q}$ is that, a number of temporal layers are generated than that of MPEG-4 which has improved the bit-stream adaptation to the network. At 1.5/10f/s coding frame rate, a bit reduction of 1160bits, $15100 \mathrm{bits},-5350$ bits is obtained for SL, BL and EL respectively for $\mathrm{t}+\mathrm{s}+\mathrm{q}$ against MPEG-4. In the same way, a gain of quality values of $2.4 \mathrm{~dB}, 2.38 \mathrm{~dB}$ and $2.32 \mathrm{~dB}$ for these rates is realised for $\mathrm{t}+\mathrm{s}+\mathrm{q}$ technique against MPEG-4 technique.

\subsection{Subjective Evaluation of $t+s+q$ Technique}

Similar procedures and guidelines employed for $\mathrm{t}+\mathrm{q}$ are used. Fig. 9 presented the results of the evaluation exercise. The gathered opinions for QCIF format revealed that, QCIF products are approximately hundred percent similar to the original videos in spatial domain. This result is shown on Fig. 9 (b). However with CIF resolution format, there are few opinions indicating slight difference among the original and $\mathrm{t}+\mathrm{s}+\mathrm{q}$ pictures. This is due to the reduction of I-frames to improve GOP hierarchical structure for better adaptation. Fig. 10 presents the achieved video quality from $\mathrm{t}+\mathrm{s}+\mathrm{q}$ technique and SL. 
Table II - $\mathrm{t}+\mathrm{s}+\mathrm{q}$ technique and MPEG-4 scalability, quality and adaptation performance

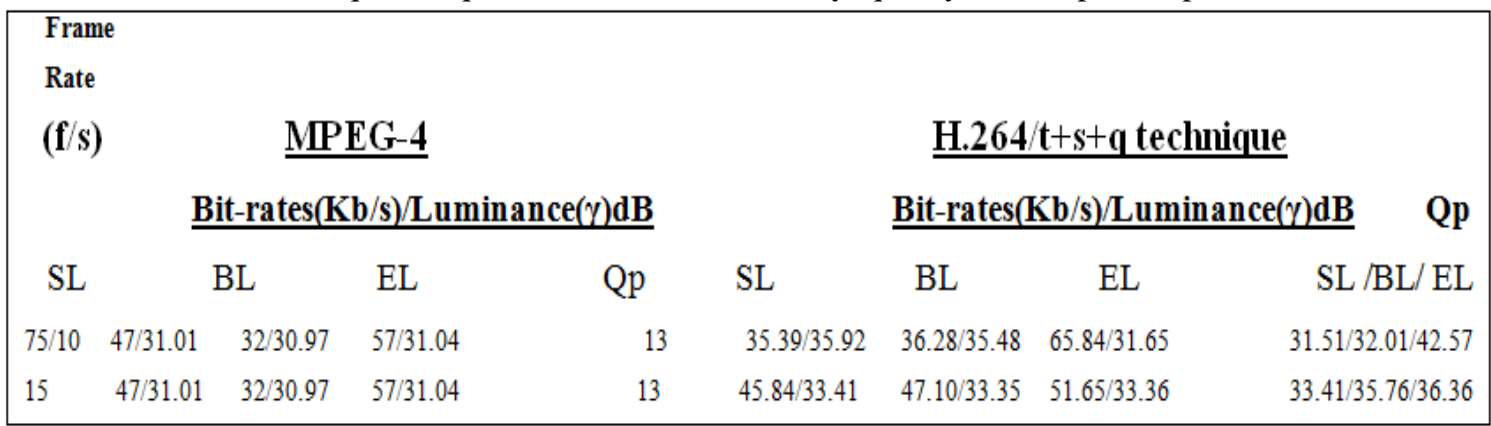

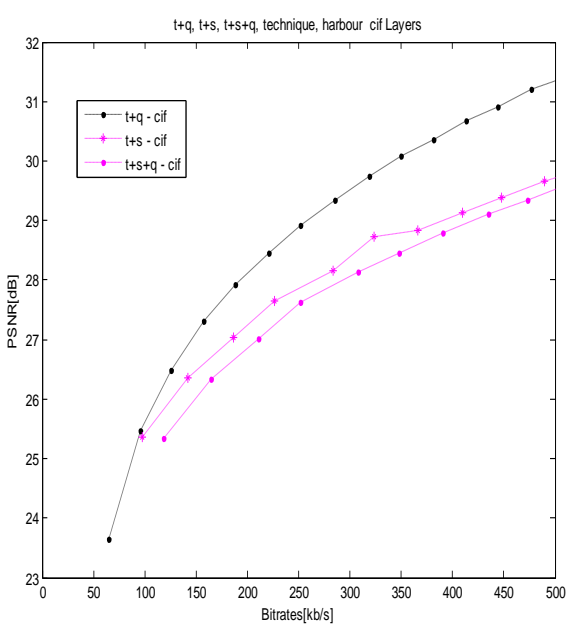

a. Harbour

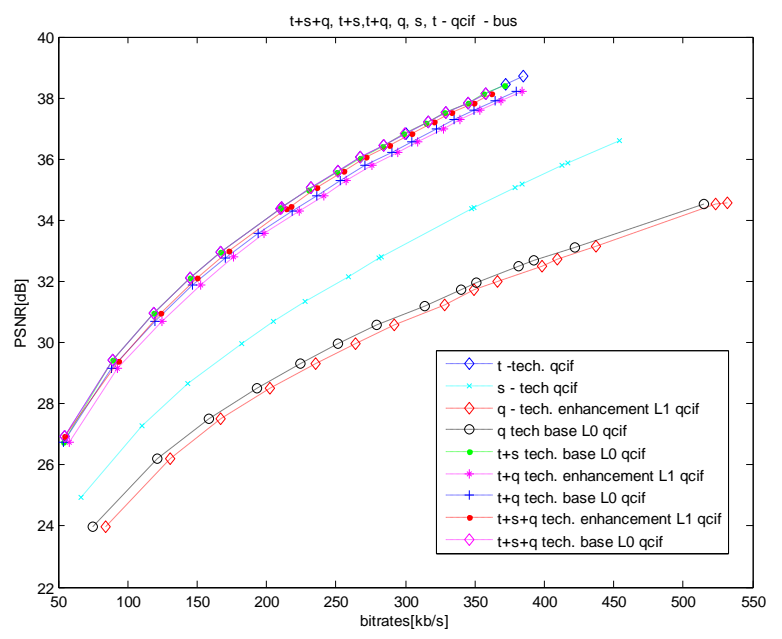

b. Bus

Fig. $7: t+s+q-$ quality and adaptation performance with other techniques.

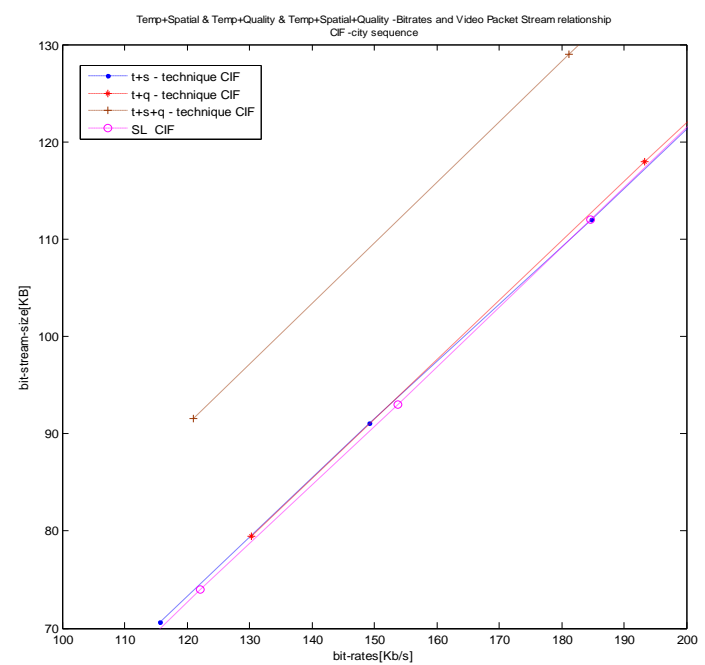

a. City

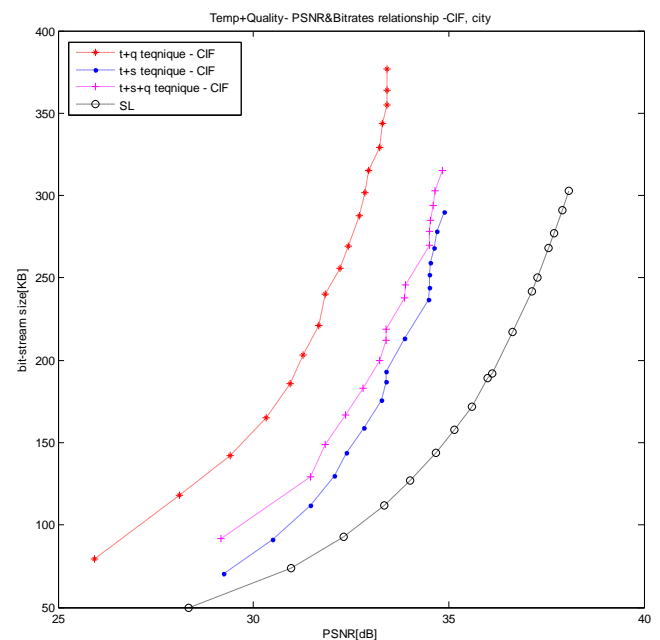

b. City

Fig. 8: Designed scalability techniques and SL (a) bit-rate $[\mathrm{Kb} / \mathrm{s}]$ and bit-stream size $[\mathrm{KB}]$ relationship (b) PSNR $[\mathrm{dB}]$ and bit-stream size $[\mathrm{KB}]$ relationship. 


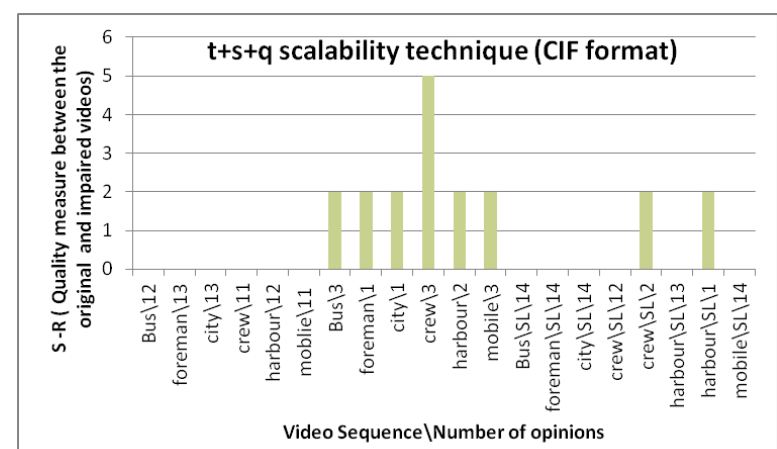

a. CIF

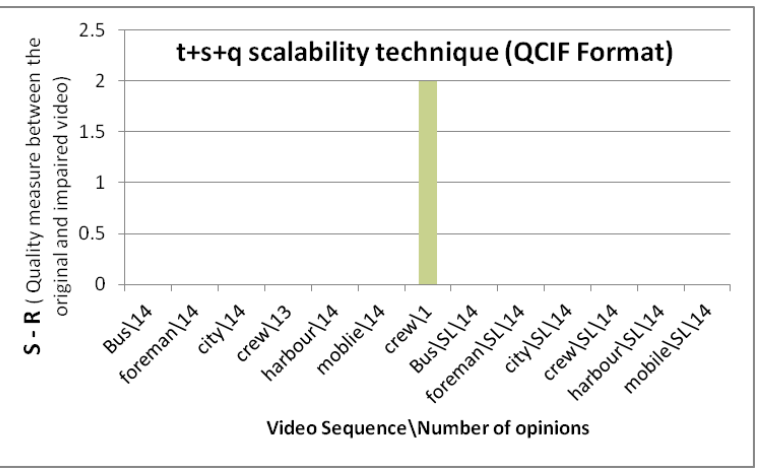

b. QCIF

Fig. 9 : $\mathrm{t}+\mathrm{s}+\mathrm{q}$ subjective quality evaluation, pair opinion scores among the original video, $\mathrm{SL}$ and $\mathrm{t}+\mathrm{s}+\mathrm{q}$ techniques.

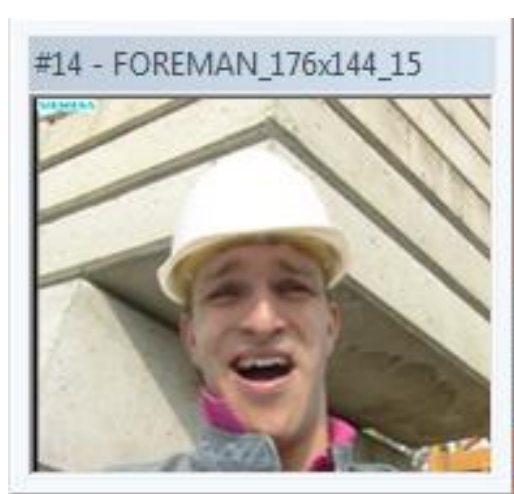

a. Pixel domain, frame 14

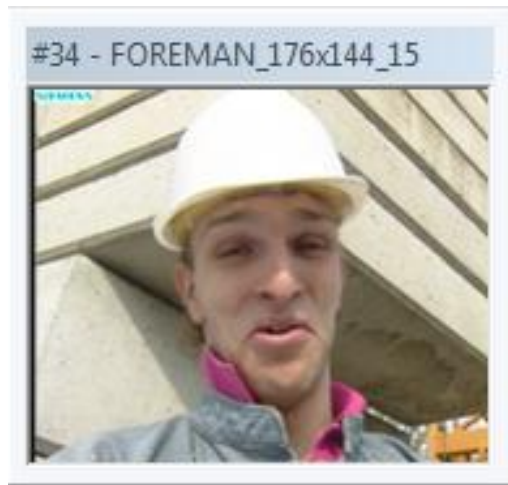

c. Pixel domain, Frame 34

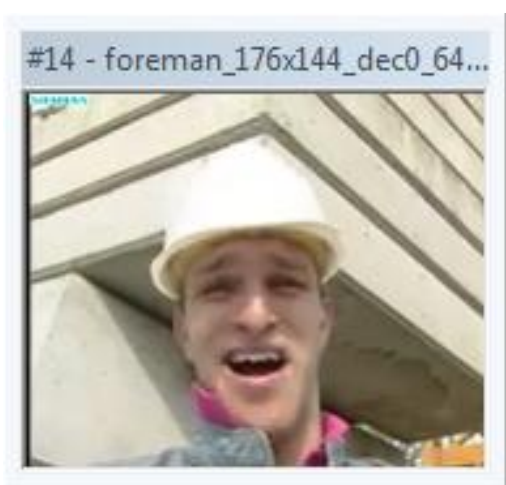

b. SL, $64 \mathrm{~Kb} / \mathrm{s}$, Frame 14

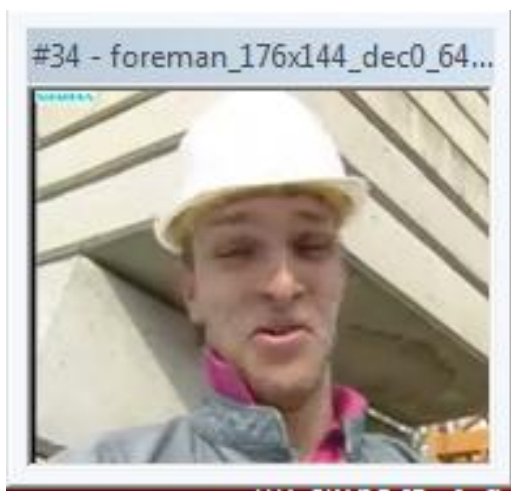

d. SL, $64 \mathrm{~Kb} / \mathrm{s}$, Frame 34

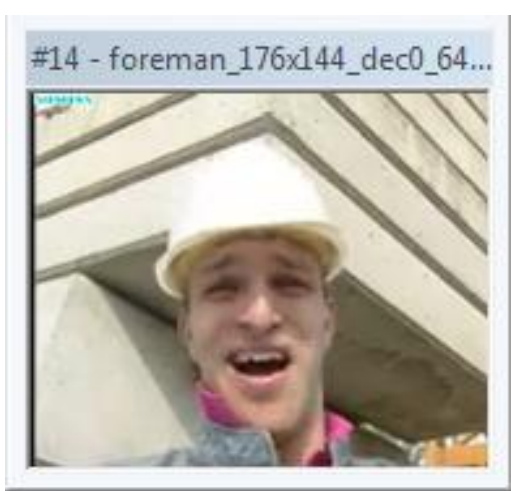

c. $\mathrm{t}+\mathrm{s}+\mathrm{q}, 64 \mathrm{~Kb} / \mathrm{s}$, Frame 14

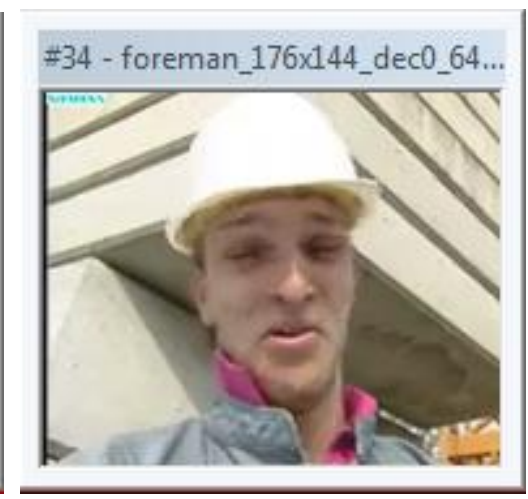

e. $t+s+q, 64 K b / s$, Frame 34

Fig. $10: t+s+q-$ subjective quality evaluation (QCIF)

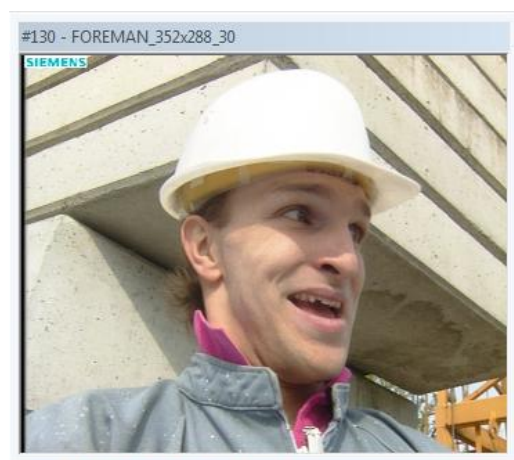

a. Pixel domain, frame 130

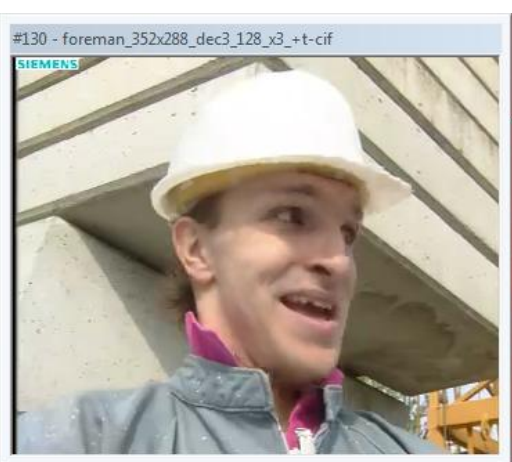

b. SL, $128 \mathrm{~Kb} / \mathrm{s}$, Frame 130, CIF

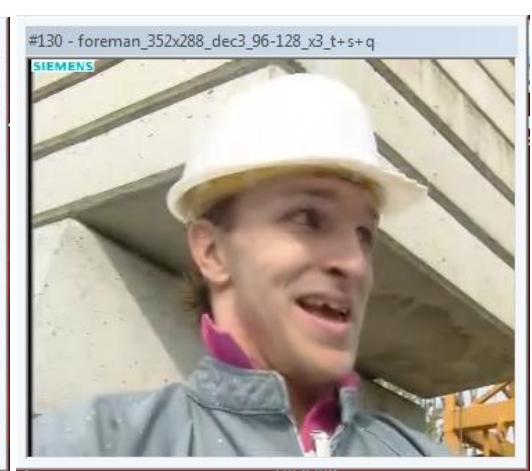

c. $\mathrm{t}+\mathrm{s}+\mathrm{q}, 128 \mathrm{~Kb} / \mathrm{s}$, Frame 130, CIF

Fig. $11: \mathrm{t}+\mathrm{s}+\mathrm{q}-$ subjective quality evaluation (CIF) 


\section{Temporal And Spatial Technique $(T+S)$}

Spatial scalability enables video adaptability for multi-display characteristics of the targets and client devices without any re-encoding requirements. The temporal scalability supports decoding of moving pictures with multiple frame rates. In this technique both spatial and temporal scalability are enabled in the bit-stream to increase the adaptation of the spatial layers. A minimum of two different spatial resolution formats are required to enable $t+s$ technique. Hence the source video must be up-sampled or down-sampled to provide second spatial picture scalability. The inclusion of temporal activity in the encoding operation allows production of several spatial picture enhancement layers for each of the two required formats. $t+s$ structure is shown Fig. 13. An experiment is conducted with harbour sequence. $1 \mathrm{x}$ CIF and $1 \times \mathrm{x}$ QCIF video sequences and a number of thirteen scalable layers are generated (7XQCIC and 6XCIF). Each of the layers takes a unique frame, Qp and bit-rate. This feature allows generation of multiple quality layers embedded in the video stream. The video stream embeds a minimum of $0.4688 \mathrm{~Hz}$ and a maximum of $30.00 \mathrm{~Hz}$ frame rates. The variable frame rates were encoded with variable bit-rates having a minimum of $51.50 \mathrm{~Kb} / \mathrm{s}$ and a maximum of $720.60 \mathrm{~Kb} / \mathrm{s}$ discrete levels.

\subsection{Objective Evaluation of $t+s$ Technique}

Experimental results for $\mathrm{t}+\mathrm{s}$ and $\mathrm{s}$ techniques are presented in Fig.12 for several sequences. From Fig. 12 (a), it is shown that for a video quality of $32 \mathrm{~dB}, 28 \mathrm{~dB}$ and $34 \mathrm{~dB}, 100 \mathrm{~Kb} / \mathrm{s}, 50 \mathrm{~Kb} / \mathrm{s}$ and $150 \mathrm{~Kb} / \mathrm{s}$ bandwidths are respectively required for $\mathrm{t}+\mathrm{s}$. To achieve similar quality with s-technique, $400 \mathrm{~Kb} / \mathrm{s}, 300 \mathrm{~Kb} / \mathrm{s}$ and $500 \mathrm{~Kb} / \mathrm{s}$ are required. This equated to bits reduction of 200000 to $400000 \mathrm{bits} / \mathrm{sec}$ for $\mathrm{t}+\mathrm{s}$ against $\mathrm{s}$ technique. These profits of $\mathrm{t}+\mathrm{s}$ technique over s-technique are achieved due to efficient prediction employed in $\mathrm{t}+\mathrm{s}$ by inclusion of temporal scalability. Temporal redundancies are removed and therefore better compressed coded bits are obtained. Similar results are obtained in Fig.12 (b) favouring the use of $\mathrm{t}+\mathrm{s}$ for better adaptation.

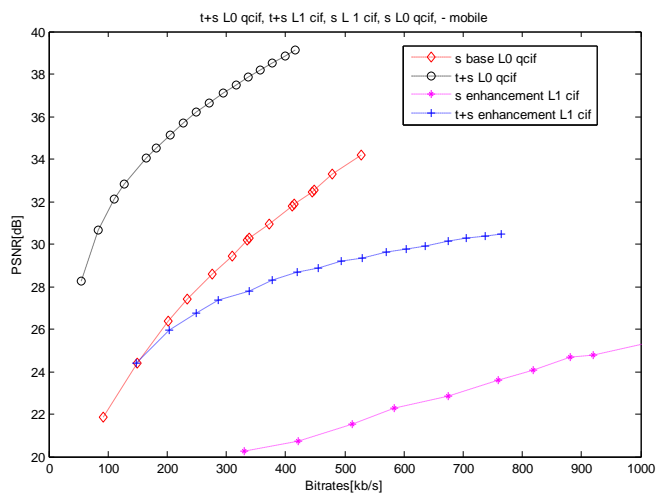

a. Mobile

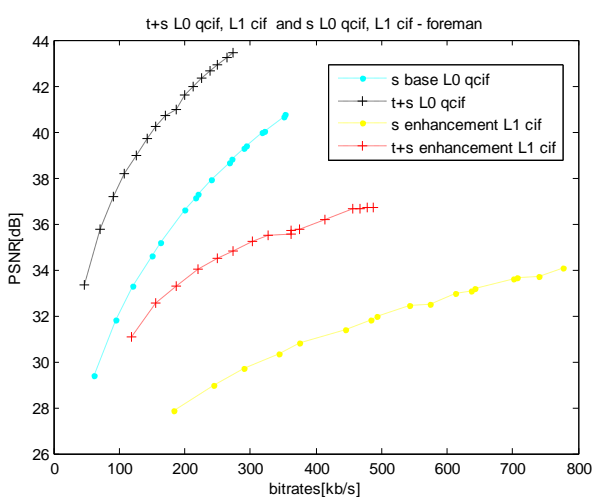

b. Foreman

Fig.12 : t+s technique - Objective Quality Performance.

Table III - $\mathrm{t}+\mathrm{s}$ technique and MPEG-4 scalability adaptation and quality performance

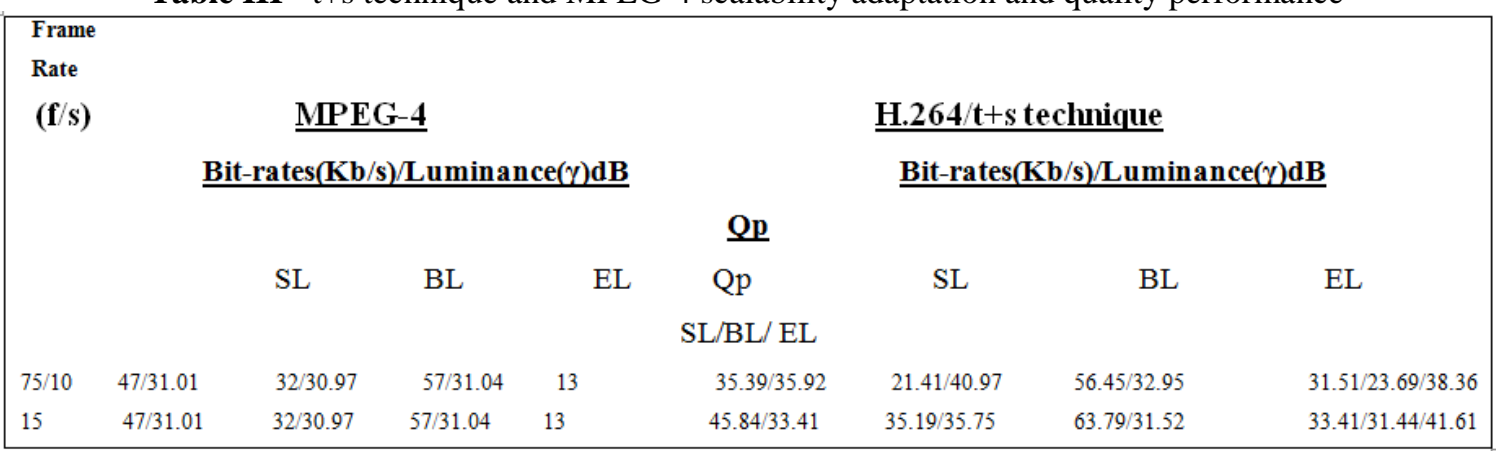

It is shown from Table III that coding with 7/10f/s frame rate, $\mathrm{t}+\mathrm{s}$ technique achieved bits reduction of 7000bits, 10590bits and 550bits per second for SL, BL and EL respectively. Similarly t+s technique gained a quality difference of $4.95 \mathrm{~dB}, 10 \mathrm{~dB}$ and $1.91 \mathrm{~dB}$ for SL, BL and EL respectively. At coding frame rate of $15 \mathrm{f} / \mathrm{s}$, $\mathrm{t}+\mathrm{s}$ technique gained 1160bits, -3190 bits and -6790 bits per second for SL, BL and EL respectively. Similarly t+s technique quality is bettered by $4.18 \mathrm{~dB}, 4.78 \mathrm{~dB}$ and $0.48 \mathrm{~dB}$. It is observed in the $15 \mathrm{f} / \mathrm{s}$, MPEG- 4 technique gained over $t+s$ technique on bits reduction while the $t+s$ quality values are higher. The adaptive quantisation used with $\mathrm{t}+\mathrm{s}$ favoured used of high Qp values of 31.44 and 41.61 to adjust the picture quality. 


\subsection{Subjective Evaluation of $t+s$ Technique}

Fig. 14 shows frame 141 and 35 for $\mathrm{t}+\mathrm{s}$, SL and original video subjective results (QCIF). The method and procedures described for $\mathrm{t}+\mathrm{q}$ are obeyed. Majority of the participants numbered thirteen out of the total fourteen participants perceived $\mathrm{t}+\mathrm{s}$-cif format with excellent quality product. The results are presented in Fig. 16. On the QCIF format of $\mathrm{t}+\mathrm{s}$ technique, approximately hundred percent of the participants recommended that, the $\mathrm{t}+\mathrm{s}$ output picture and the original video in pixel domain are the same in visual quality. This recommendation is a given view by many of the experts and none-experts in the field.

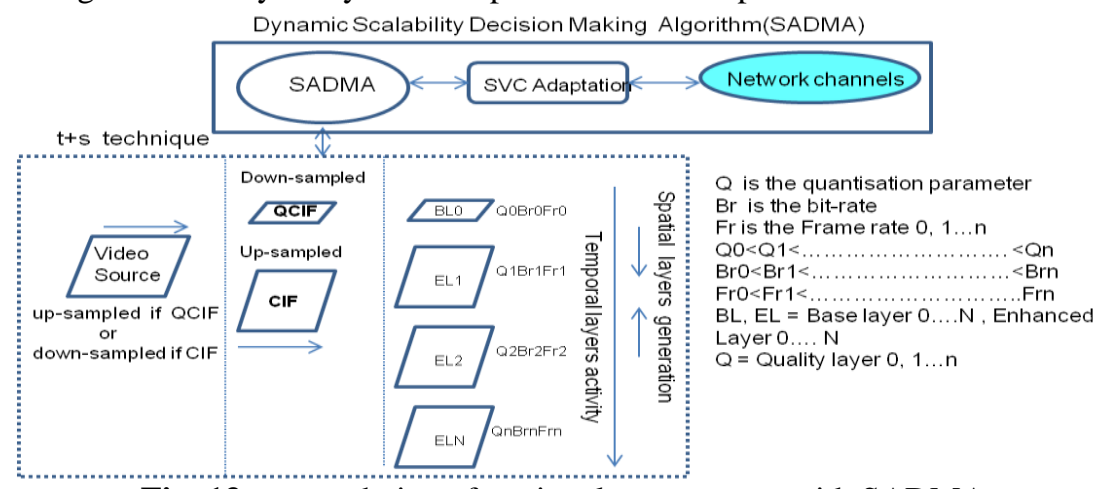

Fig. 13: $t+s$ technique functional components with SADMA

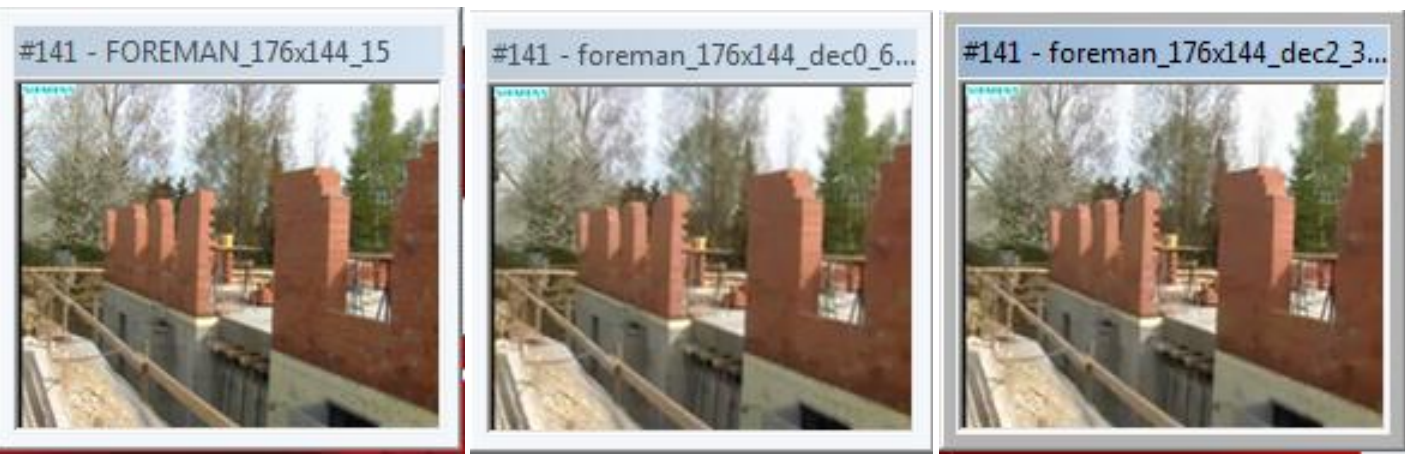

a. Pixel domain, frame 141

b. SL, $64 \mathrm{~Kb} / \mathrm{s}$, Frame 141

c. $t+s, 64 \mathrm{~Kb} / \mathrm{s}$, Frame 141
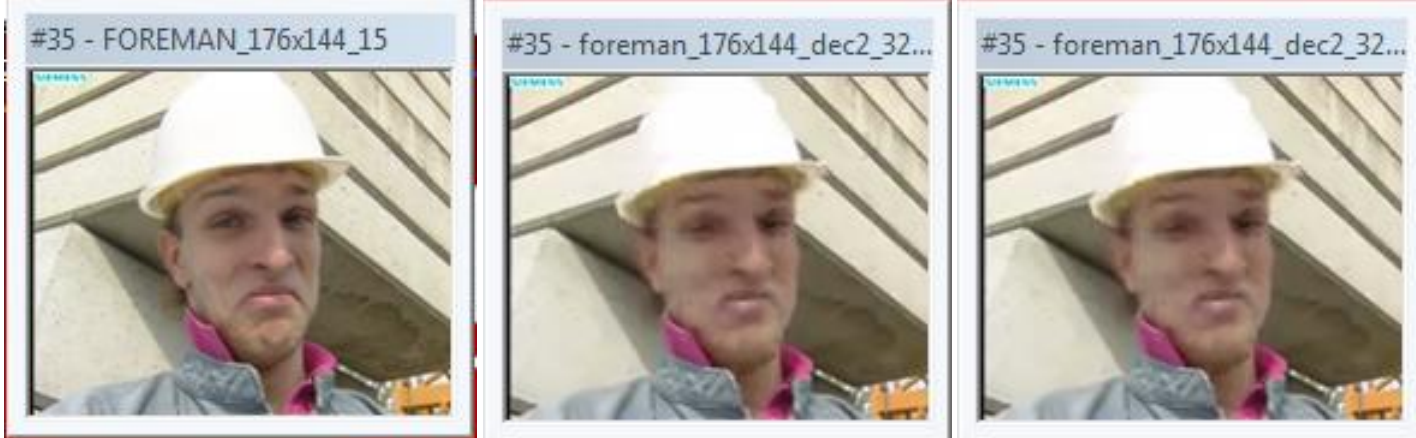

c. Pixel domain, Frame 35

d. SL, 32Kb/s, Frame 35

e. $t+s, 32 \mathrm{~Kb} / \mathrm{s}$, Frame 35

Fig. $14: t+s-$ subjective quality evaluation (QCIF)

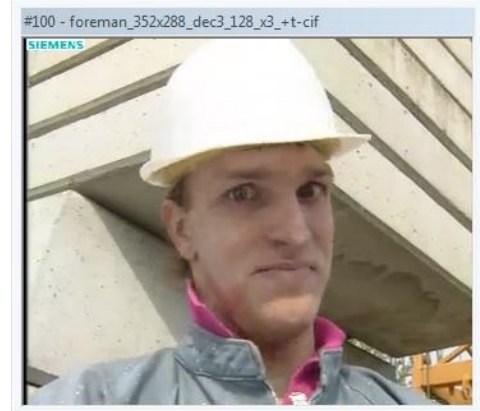

a. SL, $128 \mathrm{~Kb} / \mathrm{s}$, Frame 100, CIF

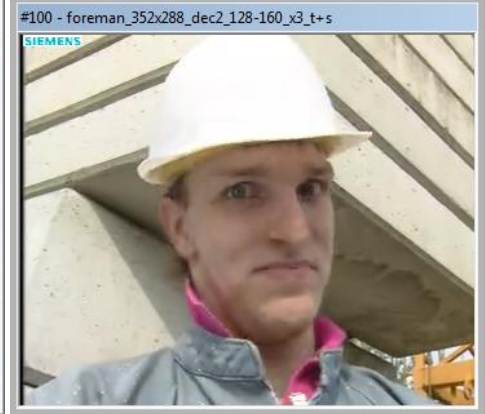

b. $\mathrm{t}+\mathrm{s}, 128 \mathrm{~Kb} / \mathrm{s}$, Frame 100, CIF

Fig. $15: t+s-$ subjective quality evaluation $(\mathrm{CIF})$ 


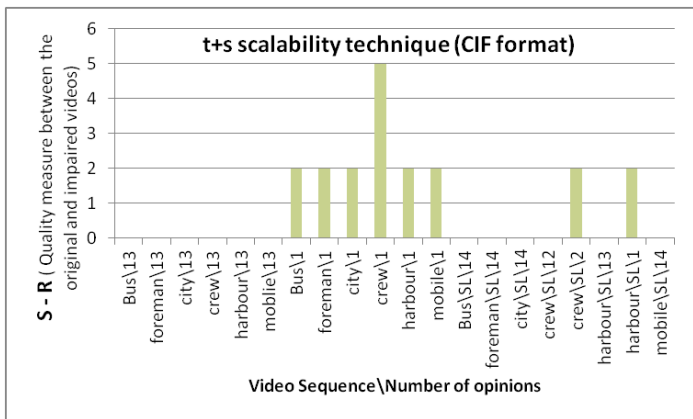

a. CIF

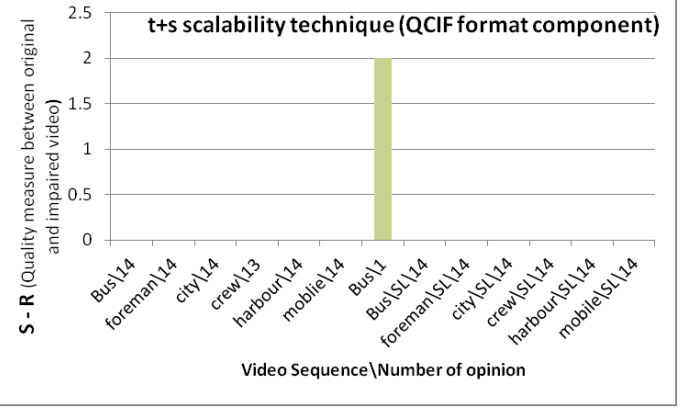

b. QCIF

Fig. $16: t+s$, Subjective performance evaluation and pair opinion views among the original, impaired and SL videos

\section{Spatial And Quality Technique (S+Q)}

Temporal scalability is reduced in this technique and hence a small number of adaptation layers are realised. This increased the number of intra-frames and hence undesirable peak rates are generated. However this will maintain a high quality picture where channels experience tolerated delays and the I-frames (key pictures) are not coded. In the case of improved adaptation, the key pictures are usually coded. In error prone and delay channels, the scalability control flexibility is reduced and might result in un-guaranteed picture quality. One other distinguishing characteristic is the ability of the technique to use higher frame rates only due to reduced skipping gap during encoding. The structure of this technique is as in Fig. 6 except the temporal activity. An experiment is conducted with foreman sequence. A total of six scalability layers are produced (2XQCIF and 4XCIF). A minimum and maximum frame rate of 15f/s and 30f/s are used.

This is because shorter frame skipping is adopted in $s+q$ technique and hence the temporal layers production is minimal. Also, this technique employs small GOP sizes which resulted for a large number of bits lessening network adaptation. The bit-stream is embedded with sub-layers of minimum and maximum bit-rate of $110.50 \mathrm{~Kb} / \mathrm{s}$ and $187.50 \mathrm{~Kb} / \mathrm{s}$ showing less flexibility to low and high rates channels.

\subsection{Objective Evaluation of $s+q$ Technique}

Experiments revealed that, the decoded picture quality and adaptation is low compared with the other techniques. From Fig. $17(\mathrm{a}, \mathrm{b}), \mathrm{s}+\mathrm{q}$ layers are under the curve where low quality values and higher bit-rates are observed as compared to other techniques. The two layers of $\mathrm{s}+\mathrm{q}$ technique L0 and L1 for both QCIF and CIF format show poor objective quality from the results as compared to $\mathrm{t}+\mathrm{s}+\mathrm{q}, \mathrm{t}+\mathrm{q}$ and $\mathrm{t}+\mathrm{s}$ scalability methods.

\subsection{Subjective Evaluation of $s+q$ Technique}

Experimental results in Fig. 18 presents that, $s+q$ produced a poor quality picture compared to SL and other techniques. This occurred due to large amount of bits reduction from encoding of large amount of key pictures. The main objective is to achieve better adaptation and therefore the design considers encoding of key pictures to reduce the number of spent bits. Fig. 18 shows the subjective quality performance for $\mathrm{s}+\mathrm{q}$ for frame 141 and 35 of foreman sequence.

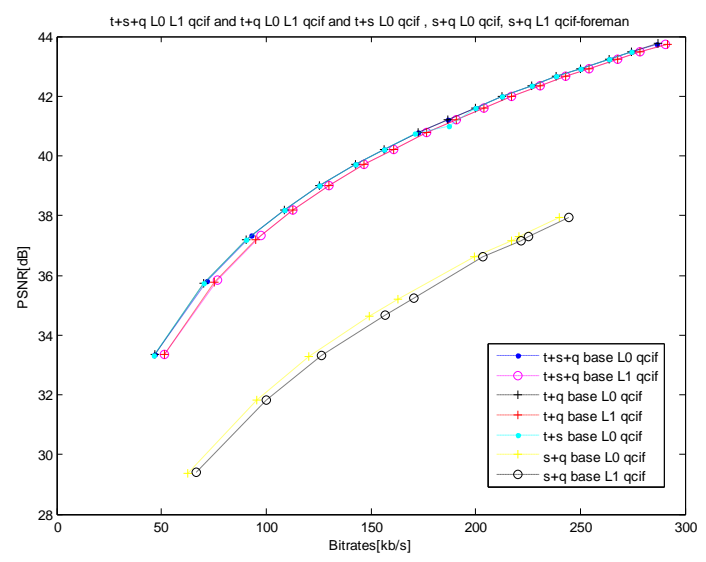

a. Foreman, QCIF

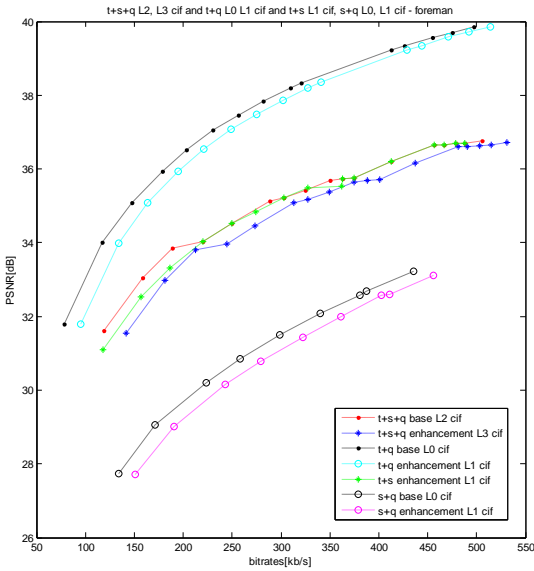

b. Foreman, CIF

Fig. 17 : s+q objective quality performance 


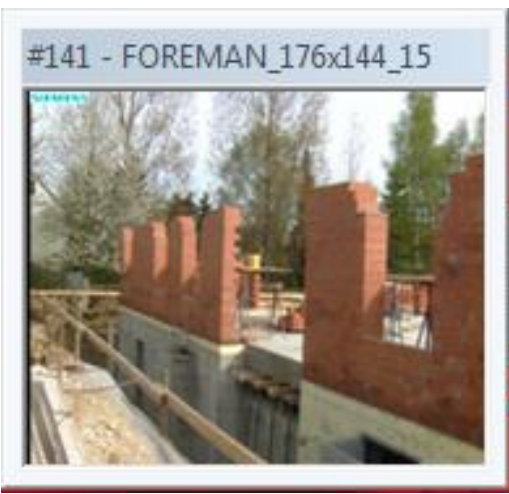

a. Pixel domain, frame 141

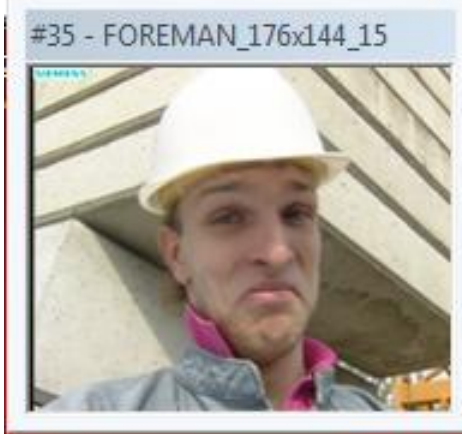

a. Pixel domain, Frame 35

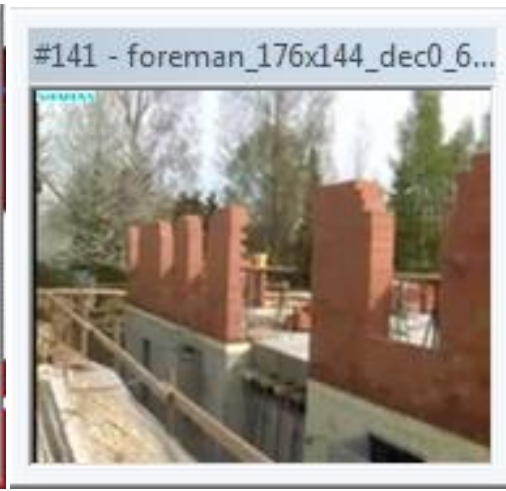

b. SL, $64 \mathrm{~Kb} / \mathrm{s}$, Frame 141

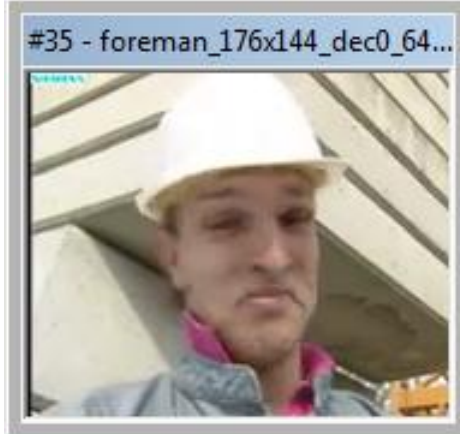

b. SL, $64 \mathrm{~Kb} / \mathrm{s}$, Frame 35

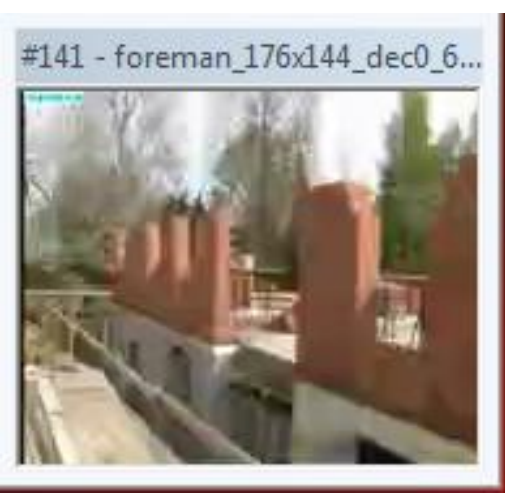

c. $s+q, 64 \mathrm{~Kb} / \mathrm{s}$, Frame 14

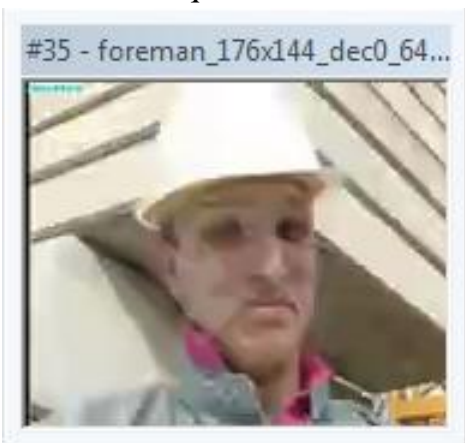

c. $s+q, 64 \mathrm{~Kb} / \mathrm{s}$, Frame 35

Fig. $18: \mathrm{s}+\mathrm{q}$ - subjective quality evaluation

This is due to additional administrative overheads included in the scalable bit-streams. With scalable bit-stream there are overheads termed as SEI messages for each layer. These include picture format, bit-rate and many others that allow sub-stream extraction, decoding and control. $\mathrm{t}+\mathrm{q}$ scalability method shows better scalability adaptation among the other developed techniques from the experimental results. In Table VIII, L0 stand for a BL0,QCIF while L1 is EL1,CIF format. Table VII shows the capability of current and developed techniques scalability adaptation and quality performance characteristics.

\section{Comparative Analysis Of The Developed Scalability Techniques}

To evaluate and compare the developed techniques, several ITU-standard sequences are used in an experiment and real time simulations. Table VIII and Table IV Present experimental results from six dissimilar ITU sequences to assess the quality and adaptation characteristics for $\mathrm{t}+\mathrm{q}, \mathrm{t}+\mathrm{s}+\mathrm{q}, \mathrm{t}+\mathrm{s}, \mathrm{SL}, \mathrm{q}$, and $\mathrm{s}$ techniques for both high/low resolution formats (CIF/ QCIF). $t+s+q, t+q, t+s$ techniques shows better adaptation characteristics compared to s+q, q, and s scalability techniques respectively. The developed techniques also show higher bitrates than the SL technique from $1-20 \mathrm{~Kb} / \mathrm{s}$ for CIF for some video sequences.

Table V : Average delay values for WIMAX, Ethernet and WILAN seeds for the scalability techniques over heterogeneous network- Resources Configuration-A

\begin{tabular}{|llll|}
\hline Technique & WIMAX average delay (secs) & Ethernet average delay (secs) & WILAN delay average \\
(secs) & & 0.005023 & \\
$\mathrm{t}+\mathrm{s}+\mathrm{q}$ & 0.3261738 & 0.052518 & 0.5309553 \\
$\mathrm{t}+\mathrm{q}-\mathrm{cif}$ & 0.3255976 & 0.0050822 & 0.5309553 \\
$\mathrm{t}+\mathrm{q}-\mathrm{qcif}$ & 0.3255976 & 0.0052338 & 0.5309553 \\
$\mathrm{t}+\mathrm{s}$ & 0.3255976 & 0.0051814 & 0.5309553 \\
SL-cif & 0.3255976 & 0.0051062 & 0.5309553 \\
SL-qcif & 0.3255976 & & 0.5309553 \\
\hline
\end{tabular}


Table VI : Average delay values for WIMAX, Ethernet and WILAN seeds for the scalability techniques over heterogeneous network- Resources Configuration-B

\begin{tabular}{|llcl|}
\hline Technique & WIMAX average delay (secs) & Ethernet average delay (secs) & WILAN delay average \\
(secs) & & & \\
$\mathrm{t}+\mathrm{s}+\mathrm{q}$ & 0.2591484 & 0.0053206 & 0.4309553 \\
$\mathrm{t}+\mathrm{q}-$ cif & 0.342392 & 0.0049672 & 0.4909655 \\
$\mathrm{t}+\mathrm{q}-\mathrm{q}$ cif & 0.342392 & 0.0053326 & 0.4808454 \\
$\mathrm{t}+\mathrm{s}$ & 0.342392 & 0.005323 & 0.4889563 \\
SL-cif & 0.342392 & 0.0051566 & 0.4889563 \\
SL-qcif & 0.342392 & 0.0053438 & 0.4889563 \\
\hline
\end{tabular}

Table VII - Scalability Layers and Adaptation Characteristics

\begin{tabular}{|c|c|c|c|}
\hline TECHNIQUE & $\begin{array}{l}\text { SCALABILITYAND } \\
\text { QUALITYLAYERS }\end{array}$ & $\begin{array}{l}\text { MINIMUM } \\
\text { BITRATE(kb/s) }\end{array}$ & $\begin{array}{l}\text { MINIMUMFRAME } \\
\text { RATE }(H z)\end{array}$ \\
\hline \multicolumn{4}{|c|}{ PREVIOUS AND CURRENT TECHNIQUES } \\
\hline Quality & 4 & 215.00 & 15.0000 \\
\hline Spatial & 3 & 215.00 & 15.0000 \\
\hline \multicolumn{4}{|c|}{ DEVELOPED TECHNIQUES } \\
\hline Temp+Quality & 26 & 29.80 & 0.4688 \\
\hline Temp+Spatial & 13 & 47.60 & 0.4688 \\
\hline Temp+Quality+Spatial & 22 & 27.10 & 0.9375 \\
\hline Quality+Spatial & 6 & 215.10 & 15.0000 \\
\hline
\end{tabular}

\section{Acknowledgement}

This research work is acknowledged to all referenced authors and to especially the SVC Joint Video Team.

\section{Conclusions}

In this research work, we developed and evaluated the performance of a set of scalability techniques. The techniques evaluation provides a support for dynamic scalability adaptation over diverse and multiresources network environment. Each of the technique can also be adopted for a specific application requirement based on its evaluated performance.

A set of schemes and algorithms including dynamic de-blocking filtering, Lambda Value Selection Algorithm, inter-layer and motion prediction are also introduced. Scalability Decision Making Algorithm is then proposed for maximum and flexible adaptation over heterogeneous networks with the usage of the developed techniques and algorithms.

Table VIII - Performance Evaluation for the Developed Scalable Video Coding Techniques

\begin{tabular}{|c|c|c|c|c|c|c|c|}
\hline \multirow[t]{2}{*}{ Video Seq } & \multicolumn{7}{|c|}{$\begin{array}{r}\text { Scalability Techniques Evaluation } \\
\underline{\text { Bit-rates }(\mathrm{Kb} / \mathrm{s}) / \mathrm{Luminance}(Y) \mathrm{dB}}\end{array}$} \\
\hline & $\mathbf{t}+\mathbf{s}+\mathbf{q}$ & $\mathbf{t}+\mathbf{q}$ & $\mathbf{t}+\mathbf{s}$ & $\mathbf{q}$ & s & SL-cif & SL- qcif \\
\hline \multirow[t]{2}{*}{ Foreman } & $47.10 / 33.35$ & $47.10 / 33.35$ & $46.55 / 33.32$ & $62.35 / 29.38$ & $62.35 / 29.38$ & $117.10 / 31.84$ & $46.55 / 33.32$ \\
\hline & $119.02 / 31.55$ & $78.26 / 31.78$ & $118.08 / 31.09$ & $134.21 / 28.44$ & $183.11 / 27.89$ & & \\
\hline \multirow[t]{2}{*}{ Crew } & $46.08 / 28.64$ & $43.99 / 28.88$ & $46.08 / 28.64$ & $51.74 / 29.17$ & $51.74 / 29.17$ & $134.99 / 28.08$ & $47.59 / 29.23$ \\
\hline & $131.58 / 27.22$ & $102.29 / 25.70$ & $126.09 / 27.39$ & $142.18 / 28.16$ & $131.88 / 27.72$ & & \\
\hline \multirow[t]{2}{*}{ City } & $38.25 / 32.55$ & $38.59 / 32.88$ & $38.25 / 32.55$ & $56.05 / 27.59$ & $40.82 / 46.73$ & $122.12 / 30.96$ & $42.93 / 33.61$ \\
\hline & $121.07 / 29.16$ & $73.06 / 26.81$ & $115.73 / 29.23$ & $102.33 / 25.72$ & $92.30 / 30.77$ & & \\
\hline \multirow[t]{2}{*}{ Mobile } & $54.25 / 28.26$ & $54.25 / 28.26$ & $54.25 / 28.26$ & $92.83 / 21.88$ & $92.83 / 21.88$ & $130.69 / 25.07$ & $54.25 / 28.26$ \\
\hline & $153.26 / 24.39$ & $86.16 / 22.14$ & $147.51 / 24.41$ & $239.24 / 20.24$ & $66.39 / 24.93$ & & \\
\hline \multirow[t]{2}{*}{ Bus } & $54.97 / 26.94$ & $53.80 / 26.74$ & $53.80 / 26.74$ & $75.27 / 23.96$ & $66.39 / 24.93$ & $146.59 / 25.09$ & $54.97 / 26.94$ \\
\hline & $153.26 / 24.67$ & $91.84 / 22.30$ & $150.50 / 24.65$ & $159.16 / 23.30$ & $150.80 / 22.61$ & & \\
\hline \multirow[t]{2}{*}{ Harbour } & $40.13 / 28.56$ & $40.13 / 28.56$ & $40.13 / 28.56$ & $61.48 / 25.21$ & $61.48 / 25.21$ & $80.60 / 25.53$ & $40.13 / 28.56$ \\
\hline & $101.21 / 25.36$ & $48.01 / 23.65$ & $97.36 / 25.37$ & $127.73 / 23.43$ & $169.74 / 22.86$ & & \\
\hline
\end{tabular}




\section{References}

[1]. H. Schwarz, D. Marpe and T. Wiegand, Overview of the scalable video coding extension of the H. 264/AVC standard, Circuits and Systems for Video Technology, IEEE Transactions on, vol. 17, pp. 1103-1120, 2007.

[2]. M. Ghanbari, Standard codecs: Image compression to advanced video coding, in 2003.

[3]. X. Li, P. Amon, A. Hutter and A. Kaup, "One-pass multi-layer rate-distortion optimization for quality scalable video coding: in Acoustics, Speech and Signal Processing, 2009. ICASSP 2009. IEEE International Conference on, 2009, pp. 637-640.

[4]. S. F. Chang and A. Vetro, "Video adaptation: concepts, technologies, and open issues," Proc IEEE, vol. 93, pp. 148-158, 2005.

[5]. S. Muhammad, Scalable and Network Aware Video Coding for advanced Communications Over Heterogeneous Networks., Brunel University London, School of Engineering, 2013.

[6]. H. Sohn, H. Yoo, C. S. Kim, W. De Neve and Y. M. Ro, "Perceptual quality measurement for scalable video at low spatial resolution in mobile environments," in Society of Photo-Optical Instrumentation Engineers (SPIE) Conference Series, 2009, pp. 20.

[7]. I. E. G. Richardson, H. 264 and MPEG-4 video compression. 2003, John Wiley\&Sons Ltd., New Jersey, 